\title{
QUEEN'S
QNEIVERSITY
BELFAST
}

\section{Optimum design of cold-formed steel portal frame buildings including joint effects and secondary members}

Phan, D. T., Lim, J., Tanyimboh, T. T., \& Sha, W. (2017). Optimum design of cold-formed steel portal frame buildings including joint effects and secondary members. International Journal of Steel Structures, 17(2), 427442. https://doi.org/10.1007/s13296-017-6005-9

Published in:

International Journal of Steel Structures

Document Version:

Peer reviewed version

Queen's University Belfast - Research Portal:

Link to publication record in Queen's University Belfast Research Portal

Publisher rights

(c) 2017 Korean Society of Steel Construction and Springer-Verlag GmbH Germany.

This work is made available online in accordance with the publisher's policies. Please refer to any applicable terms of use of the publisher.

\section{General rights}

Copyright for the publications made accessible via the Queen's University Belfast Research Portal is retained by the author(s) and / or other copyright owners and it is a condition of accessing these publications that users recognise and abide by the legal requirements associated with these rights.

Take down policy

The Research Portal is Queen's institutional repository that provides access to Queen's research output. Every effort has been made to ensure that content in the Research Portal does not infringe any person's rights, or applicable UK laws. If you discover content in the Research Portal that you believe breaches copyright or violates any law, please contact openaccess@qub.ac.uk. 


\title{
Optimum design of cold-formed steel portal frame buildings including joint effects and secondary members
}

\author{
Duoc T. Phan ${ }^{\mathrm{a}}$, James B.P. Lim ${ }^{\mathrm{b}, 1}$, Tiku T. Tanyimboh ${ }^{\mathrm{c}}$, Wei Sha ${ }^{\mathrm{d}}$
}

${ }^{a}$ Department of Civil and Construction Engineering, Curtin University Sarawak, Miri, 98009, Malaysia E-mail: phanthanh.d@curtin.edu.my; Tel.: +60 85-443 939; Fax: +60 85-443 939

${ }^{\mathrm{b}}$ Department of Civil \& Environmental Engineering, University of Auckland, Auckland, 1010, New Zealand E-mail: james.lim@auckland.ac.nz; Tel.: +64 9923 8138; Fax: +64 99238138

${ }^{c}$ Department of Civil Engineering, University of Strathclyde, John Anderson Building, Glasgow, G4 0NG, $\mathrm{UK}$

E-mail: tiku.tanyimboh@strath.ac.uk; Tel.: +44 (0) 141548 4366; Fax: +44 (0) 1415484366

${ }^{\mathrm{d}}$ School of Natural and Built Environment, Queen's University Belfast, David Keir Building, Belfast, BT9 $5 \mathrm{AG}, \mathrm{UK}$

E-mail: w.sha@qub.ac.uk; Tel.: +44 (0)28 9097 4017; Fax: +44 (0)28 90974017

${ }^{1}$ Corresponding author. 


\title{
Optimum design of cold-formed steel portal frame buildings including joint effects and secondary members
}

Duoc T. Phan ${ }^{\mathrm{a}}$, James B.P. Lim ${ }^{\mathrm{b}, 1}$, Tiku T. Tanyimboh ${ }^{\mathrm{c}}$, Wei Sha ${ }^{\mathrm{d}}$

\begin{abstract}
In steel portal frames, cold-formed steel channel sections are increasingly used as the primary framing components, in addition to the secondary members e.g. purlins and side rails. For such framing systems, the stiffness of the joints at the eaves and apex affects the bending moment distribution, as well as the frame deflections. This paper investigates the influence of two joint configurations having full rigidity and semirigidity, respectively, on the optimum design of cold-formed steel portal frames. A real-coded genetic algorithm is used to search for the most cost-effective design. It is shown that through incorporating joint effects explicitly into the design process, a more appropriate balance between the joints and the member properties can be obtained, thus optimizing material use. The study then investigates the effect of secondary members on the optimum design. It is shown that incorporating the secondary members is important for portal frames having spans less than $12 \mathrm{~m}$. For example, for a frame spacing less than $6 \mathrm{~m}$, the material cost of the primary members can be reduced by up to $15 \%$.
\end{abstract}

Keywords: Cold-formed steel, portal frames, optimisation, real-coded genetic algorithm.

${ }_{1}^{1}$ james.lim@auckland.ac.nz; Tel.: +64 9923 8138; Fax: +64 99238138 


\section{Introduction}

Cold-formed steel (CFS) portal framing systems are a popular form of construction in the UK for light industrial buildings and warehouses etc., having a typical span of around $12 \mathrm{~m}$. Such frames are lightweight, economical, easy to install and erect, which is viable alternative to conventional hot-rolled steel frames (Lim and Nethercot 2003). For portal framing system considered in this paper, CFS channel-sections are used for the column and rafter members, and Z-sections are used for the purlins and side rails.

It is well-known that the use of CFS members for portal frames requires a high rigidity of the joints at the knees and apex to transfer the applied loads through bending action of the members. Standard design practice normally assumes full rigidity (Mills and LaBoube 2004). Although semi-rigid joints may also be allowed in the analysis, this is not common practice for designing CFS portal frames.

A form of rigid-joints for CFS portal frames were proposed by Kirk (1986) (see Fig. 1), having a moment capacity equal to that of the channel section being connected. As can be seen from Fig. 1, such joints were formed through the swages being rolled on the web of channel sections and brackets, which are rigidly interlocked at the eaves and apex under action of bending moment. With longer frame spans, to increase the load carrying capacity of CFS portal frames, knee braces can be included at the eaves (see Fig. 1(b)). However, this type of joint configuration is expensive and can be difficult to assemble on site.

Practical design cold-formed steel portal framing systems often use a joint configuration with details as shown in Fig. 2. As can be seen, the eaves and apex joints are formed through plane brackets bolted to the web of cold-formed steel channel sections, being connected with nine bolts used for each connection. It should be noted that such joints are semi-rigid and have finite connection-lengths, owing to the elongation of the bolt holes in both the brackets and channel-sections under applied loads (Lim and Nethercot 2004). Intuitively, semi-rigidity and finite connection-length of the joints affect on the bending moment distribution, as well as the frame deflections. In order to obtain a realistic and reasonable performance of such general framing system, the influence of joint flexibility on the frame design needs to be accounted for, and so this effect is considered in this paper.

The design optimisation of hot-rolled steel portal frames using genetic algorithm (GA) has previously been considered in the literature (Toropov and Mahfouz 2001, Saka 2003, Issa and Mohammad 2010). Saka (2003) used a binary-coded GA to minimise the weight of a hot-rolled steel portal frames, subject only to gravity load. Four distinct discrete variables were used, namely, the cross-section sizes of the columns and rafters, and both length and depth of the eaves haunch. The optimisation procedure identified the most appropriate sections for the members from a list of standard Universal Beam (UB) sections; similarly, the most appropriate haunch size was selected from a list of pre-defined discrete haunch dimensions. Thereafter, Issa and Mohammad (2010) continued the work of Saka and used a binary-coded GA with a number of population groups implementing genetic operations in parallel, referred to as distributed GA. A binary string length of five bits was applied that included both universal beam and universal column sections. A number of variable mutation schemes, proposed to improve the diversity of the population, were shown to increase the probability of achieving the optimum solution. However, one of the limitations of binary-coded GAs is the extra computational complexity 
of the algorithm associated with continuous decision variables. Phan et al. (2013a) investigated the effect of serviceability limits on optimal design of steel portal frames. The frames were designed under ULS with a plastic design strategy with frame behaviour compared to the example created by Issa and Mohammad (2010) and benchmarked by Saka (2013). A modified GA was used with a niching technique which was shown to be highly effective in maintaining diversity in the population, preventing premature convergence due to overrepresentation of the best individuals in the mating pool. It was shown that the plastic design allowed for lighter solutions under the gravity load case compared to the elastic equivalent. McKinstray et al. (2015a, 2016) conducted the design optimisation of long-span steel portal frames using fabricated beams to Eurocode 3, including topological asymmetry. The optimisation of single-storey non-domestic steel framed buildings using photovoltaic panels for net-zero carbon impact was also considered (McKinstray et al. 2015b).

In contrast to hot-rolled steel sections, the shape of CFS cross-sections can be optimised to increase their load carrying capacity, leading to more efficient and economical structural systems. Work on optimising such CFS cross-sections has been described by (Schafer et al. 2010, Gilbert et al. 2012a-b, Ma et al. 2015, Wang et al. 2016a-b, Ye et al. 2016 a-b). For optimization of the portal framing system, a design optimisation ofCFS portal frames with rigid-joints was carried out by Phan et al. (2013b), using Australian design code of practice for cold-formed steel AS/NZS 4600 (2005) for the member checks. In the frame analysis model, the joints were assumed to be capable of sustaining the full moment capacity of the channel-sections being connected. The objective function was the minimum material cost per square meter on plan. The effect of building topology, i.e. pitch of the roof and the frame spacing was investigated. However, design on a bare frame was carried out, neglecting the serviceability limit state. More recently, Phan et al. (2015) and Wrzesien et al. (2016) considered the effect of stressed-skin on cladded portal frame buildings. Through focusing only on optimising the material cost of main frame, those researchers have not considered the effect of the material cost of the secondary members (i.e., purlins, side rails and cladding) on the overall cost of the building. It is worth noting that with cold-formed steel portal frames where the spans being considered are modest, the cost of the secondary members can be considerable.

This paper presents the design optimisation of the CFS portal frame building which includes the influences of joint configuration and secondary members. The material cost of the primary members, joints and secondary members (i.e. purlins, side rails and cladding) for one full bay of the building are minimised using real-coded niching genetic algorithm (RC-NGA). Effect of building topology, i.e. frame spacing and pitch, on the optimum design is also taken into account. The CFS framing system is designed to both ultimate and serviceability limit states using the The Steel Construction Institute recommendations for deflection limits for portal frames (see Table 1). It should be noted that the length of building is long enough to neglect the stressedskin effect through cladding system (Phan et al. 2015).

Most of the design problems considered in this paper such as strength and stiffness of bolted joints remain outside the scope of British Standards as well as Eurocodes. These subjects were studied by different researchers and references were made to different design codes based on time of the publication (Wrzesien et al. 2012, Dubina et al. 2012). The design equations for joint characteristic were chosen based on research predating publication of Eurocodes thus the British Standards were chosen for consistency. 


\section{Idealisation of joint configuration having semi-rigidity}

The structural behaviour of the joint configuration shown in Fig. 2 has been investigated using both full-scale tests and frame analysis (Lim and Nethercot 2004, Wrzesien et al. 2012). Such joints cannot be treated as rigid; under load, the bolt holes elongate, leading to significant rotation in the joints.

For the analysis of frames having semi-rigid joints, the rotational stiffness needs to be determined (Lim and Nethercot 2003, Lim and Nethercot 2004). Fig. 3 shows the layout of a typical bolt group. As can be seen, nine bolts per group are used for the joint. When the bolt group resists an external moment $\mathrm{M}$, it rotates about a point known as centre of rotation, which is at the centre of the bolt group due to symmetrical configuration of the joint (Kulak et al. 1987, Davies 1991, Zandanfarrokh and Bryan 1992). The resisting force $F_{i}$ at each bolt hole is proportional to its distance $\mathrm{d}_{\mathrm{i}}$ from the centre of rotation and acts in a direction of moment perpendicular to the line drawn from the bolt hole to the centre of rotation. It should be noted that the centre of the rotation is assumed to coincide with the centre of the bolt-group. Experimental research on portal frames has previously shown that such an assumption is reasonable and approximates the stiffness of cold-formed steel frames with sufficient accuracy (Lim and Nethercot 2004). The rotation stiffness of the bolt group $\mathrm{k}_{\mathrm{B}}$ for a $3 \times 3$ bolt group is as follows:

$$
\mathrm{k}_{\mathrm{B}}=\frac{3}{2}\left(\mathrm{a}_{\mathrm{B}}^{2}+\mathrm{b}_{\mathrm{B}}^{2}\right) \mathrm{k}_{\mathrm{b}}
$$

where
$a_{B} \quad$ is the length of bolt group
$b_{B} \quad$ is the breadth of bolt group
$\mathrm{kb} \quad$ is bolt hole elongation stiffness depending on the web thickness of CFS channel sections.

For frame analysis, the semi-rigidity of the joints is idealised by a rotational spring at the centre of rotation of the bolt-group. The distance from intersection of the members to the centre of rotation of each bolt-group is referred to as the effective length of the connection (see Fig. 4).

\section{Frame description and load combinations}

The geometrical parameters of the portal frame shown in Fig. 5 are as follows: span of frame $\mathrm{Lf}_{\mathrm{f}}$, height to eaves $h_{f}$, pitch of frame $\theta_{f}$, and frame spacing (or bay spacing) $b_{f}$. It was assumed that the column bases are pinned. In this paper, a frame having span of $12 \mathrm{~m}$ and height of eaves of $3 \mathrm{~m}$ is considered and referred to as Reference Frame. The cross-section for the primary members i.e., columns and rafters is taken from the list of 18 coldformed channel steel sections, which can either be used singly or back-to-back (Phan et al. 2015). For frame using rigid joint configuration, it is obvious that the swages on the web of channel-section improve the load carrying capacity of the members. However, for simplifying the checking procedure and obtaining a conservative design, it should be noted that the section properties and member checks are based on plane channel-sections and therefore ignore the benefit of the swages.

The primary members are laterally restrained by purlins and side rails, using the Zed sections (Fig. 6). The single span system is assumed with the sleeved connection (Fig. 7) at all penultimate supports, as well as at 
alternative internal supports, which can be applied to roof pitches up to $30^{\circ}$. According to steel manufacturer's catalogues, the design guide for the purlins and side rail provides the load tables with ultimate load capacities under gravity and wind uplift loads for a deflection limit of $b_{f} / 180$. It is worth noting that the Steadmans catalogue shows that the minimum and maximum spans for the purlins and side rails under the action of gravity load and wind uplift is $3.0 \mathrm{~m}$ and $12.0 \mathrm{~m}$, respectively (Steadmans 2012a).

The framing system is designed under the dead load (DL) of $0.15 \mathrm{kN} / \mathrm{m}^{2}$ and live load (LL) of $0.6 \mathrm{kN} / \mathrm{m}^{2}$. In this paper, a dynamic wind pressure $\left(\mathrm{q}_{\mathrm{s}}\right)$ of $1.0 \mathrm{kN} / \mathrm{m}^{2}$ is adopted. Both transverse and longitudinal wind loads are considered. In accordance with BS 6399-2 (2002), the design wind pressure (p) is calculated as follows:

$$
\mathrm{p}=\mathrm{q}_{\mathrm{s}}\left(\mathrm{C}_{\mathrm{pe}}-\mathrm{C}_{\mathrm{pi}}\right)
$$

where

$$
\begin{array}{ll}
\mathrm{C}_{\mathrm{pe}} & \text { is the external pressure coefficient } \\
\mathrm{C}_{\mathrm{pi}} & \text { is the internal pressure coefficient }
\end{array}
$$

For buildings of normal permeability, without dominant openings, Cpi has a minimum value of -0.3 for suction, and a maximum value of 0.2 for pressure. Six wind load cases (WLC1 to WLC6) as shown in Fig. 8 are calculated. Thereafter, the building is designed with the ultimate limit state using four ultimate load combinations (ULCs), in accordance with BS 5950-1 (2000) as shown in Table 1. Also, the frame is also checked at the serviceability limit state under the action of two serviceability load combinations (SLCs). It should be noted that the same ultimate limit state load combinations are applied to the design of the purlins, side rails and cladding.

\section{Frame analysis and member designs}

A first-order elastic analysis is used owing to the assumption of small displacement of the frame. However, in the case of second-order effects being required, the amplified moment method could be adopted and applied to the loadings. The finite element program ANSYS was used for the purpose of the structural analysis, in which BEAM3 element was used for the columns and rafters. Forty elements were used for the column and rafter members, and five elements for eaves and apex joints. Bernoulli's beam theory is assumed, in which the effect of cross-section warping under shear stress action is neglected. It should be noted that although the BEAM188 element includes warping, use of BEAM188 element requires the pre-defined section dimensions to be input (ANSYS 2009), which is not applied for CFS channel sections.

To analyse frame having semi-rigid joints, parameters used to define CFS portal frame are shown in Fig. 9. For the eaves joints, the effective length of the bolt-group connecting the column and rafter to the bracket are $l_{e c}^{\prime}$ and $1_{e r}^{\prime}$, respectively. Similarly, the effective length of the bolt-group connecting the rafter to the apex bracket is $1_{a r}^{\prime}$. Also, frame members are each connected with bracket at the rotational centre of bolt-groups at the eaves and apex joints, through using rotational spring elements with stiffness mentioned in Eq. 1. For modelling the semi-rigidity of the joints in ANSYS, a rotational spring element of zero size connected with two coincident nodes at the joint positions (COMBIN40) was used.

The frame analysis is embedded in the minimum cost optimisation RC-NGA framework to analyse each candidate solution in every generation that evolves towards better solutions following the principle of survival 
of the fittest. For each ultimate load combination, the bending moment, shear force and axial force diagrams of the frame members are determined. These results are then passed to design modules to carry out the member checks at the critical sections or segments between two lateral restraints. The section capacities in axial, shear, and bending are calculated using the effective width method. The axial, moment and shear strengths of the columns and rafters, as well as combined strength capacities, are determined in accordance with BS 5950 Part 5 (1998). The Young's modulus and yield strength of the cold-formed steel used for the members is $205 \times 10^{3} \mathrm{~N} / \mathrm{mm}^{2}$ and $390 \mathrm{~N} / \mathrm{mm}^{2}$, respectively. For serviceability limit state checks, the deflections at the eaves and apex should satisfy the serviceability limits as mentioned in Table 2 .

For purlins, side rails and the cladding design, it is worth noting that the cold-formed steel manufacturer from industry also provides the design facilities with the ultimate load tables for designing purlins, side rails. The load table for cladding capacity is shown in Table 3. Based on the layout of purlins and side rails, the critical load $\left(\mathrm{p}_{\text {design }}\right)$ acting on these members, will be determined from all ultimate load combinations and then be compared against the load capacity $\left(\mathrm{p}_{\mathrm{c}}\right.$ ) for purlins, side rails and claddings from the load tables provided by steel manufacturer's catalogue (Steadmans 2012a, b). The typical design constraint for the secondary members is as follows:

$$
\frac{\mathrm{p}_{\mathrm{design}}}{\mathrm{p}_{\mathrm{c}}} \leq 1
$$

\section{Optimisation model}

The objective of the design optimisation is to minimise the material cost of the channel-sections and brackets for the main frame and secondary members per unit floor area for one full bay of the building, whilst satisfying the design constraints basing on the code of practice. Material cost of the main frame, joint's details and secondary members for one bay is expressed in terms of the material cost per square metre of the floor of the building, referred to as unit cost, as follows:

$$
\mathrm{C}=\frac{1}{\mathrm{~L}_{\mathrm{f}} \mathrm{b}_{\mathrm{f}}}\left[\sum_{\mathrm{i}=1}^{\mathrm{m}} \mathrm{c}_{\mathrm{i}} \mathrm{l}_{\mathrm{i}}+\mathrm{w}_{\mathrm{br}} \mathrm{c}_{\mathrm{br}}\right]
$$

where:

$$
\begin{aligned}
& \mathrm{C} \\
& \mathrm{C}_{\mathrm{i}} \quad \begin{array}{l}
\text { is the cost of the building per square meter of floor area } \\
\text { are the costs per unit length of cold-formed steel sections for frame members } \\
\text { and secondary members }
\end{array} \\
& \mathrm{l}_{\mathrm{i}} \quad \begin{array}{l}
\text { are the lengths of cold-formed steel frame members } \\
\mathrm{m}
\end{array} \\
& \mathrm{c} \text { is the number of structural members in the portal frame } \\
& \mathrm{Cbr} \quad \text { is the cost per unit weight of the brackets } \\
& \mathrm{Wbr}
\end{aligned}
$$

The optimisation model is solved with a genetic algorithm that employs constraint violation penalties. All essential design constraints should be satisfied and, consequently, the constraints are normalised to standardise the constraint violations. The normalised forms of the design constraints (see Phan et al. 2015) or unity-factors are expressed as follows:

$$
\mathrm{g}_{1}=\frac{\mathrm{F}_{\mathrm{t}}}{\mathrm{P}_{\mathrm{t}}}+\frac{\mathrm{M}_{\mathrm{x}}}{\mathrm{M}_{\mathrm{cx}}}-1 \leq 0
$$




$$
\begin{aligned}
& \mathrm{g}_{2}=\frac{\mathrm{F}_{\mathrm{c}}}{\mathrm{P}_{\mathrm{cs}}}+\frac{\mathrm{M}_{\mathrm{x}}}{\mathrm{M}_{\mathrm{cx}}}-1 \leq 0 \\
& \mathrm{~g}_{3}=\frac{\mathrm{F}_{\mathrm{c}}}{\mathrm{P}_{\mathrm{c}}}+\frac{\mathrm{M}_{\mathrm{x}}}{\mathrm{M}_{\mathrm{b}}}-1 \leq 0 \\
& \mathrm{~g}_{4}=\left(\frac{\mathrm{F}_{\mathrm{v}}}{\mathrm{P}_{\mathrm{v}}}\right)^{2}+\left(\frac{\mathrm{M}_{\mathrm{x}}}{\mathrm{M}_{\mathrm{cx}}}\right)^{2}-1 \leq 0 \\
& \mathrm{~g}_{5}=\frac{\mathrm{F}_{\mathrm{w}}}{\mathrm{P}_{\mathrm{w}}}-1 \leq 0 \\
& \mathrm{~g}_{6}=\frac{1}{1.5}\left(1.1 \frac{\mathrm{F}_{\mathrm{w}}}{\mathrm{P}_{\mathrm{w}}}+\frac{\mathrm{M}_{\mathrm{x}}}{\mathrm{M}_{\mathrm{cx}}}\right)-1 \leq 0 \\
& \mathrm{~g}_{7,8,9}=\frac{\mathrm{p}_{\text {design }}}{\mathrm{p}_{\mathrm{c}}}-1 \leq 0 \\
& \mathrm{~g}_{10}=\frac{\delta_{\mathrm{e}}}{\delta_{\mathrm{e}}^{\mathrm{u}}}-1 \leq 0 \\
& \mathrm{~g}_{11}=\frac{\delta_{\mathrm{a}}}{\delta_{\mathrm{a}}^{\mathrm{u}}}-1 \leq 0
\end{aligned}
$$

The constraints for the ultimate limit state design for primary members are $g_{1}$ to $g_{5}$ and $g_{7}, g_{8}$ and $g_{9}$ for purlins, side rails and cladding checks, respectively. Serviceability limit state design constraints are $g_{10}$ and $g_{11}$, in which $\delta_{\mathrm{e}}$ and $\delta_{\mathrm{a}}=$ deflections at eaves and apex, respectively. Design constraint $\mathrm{g}_{6}$ is applied for examining the strength of semi-rigid joint configuration (Dubina et al. 2012). It should be noted that superscript $u$ indicates the maximum permissible deflection.

A real-coded niching genetic algorithm (RC-NGA) was coded to solve the optimisation problem with constraints as shown in Eqs. 5(a-i). The advanced characteristic of real-coded GAs is that genetic operators are directly applied to the design variables without coding and decoding as with binary GAs (Deb 2001). The optimal algorithm used in this paper randomly generates a set of solutions known as initial population. From this population, the next generation of solutions is evolved by conducting three genetic operations: binary tournament selection, crossover, and mutation. It is worth noting that the process of random selection in the binary tournament ensures that the best solutions in the population will not dominate the mating pool, as in the proportional selection method. The diversity of the population is thus preserved to increase the exploration component of the algorithm (Deb 2001).

Several researchers have investigated the diversity of population for GA from different perspectives (Michalewicz 1992). In this study, the niching strategy is applied into RC-GA's selection and crossover operators to help maintain the population still scattering throughout the evolutionary process. It is observed that the offspring produced through every generation is well distributed around the potential regions containing the optima solutions (Deb 2000, Phan et al. 2013). 
Niching is conducted by randomly selecting two individuals from the current population. If a normalized Euclidean distance smaller than a pre-defined distance, or in the same niche, they are allowed to become mating partners (Deb 2001). This procedure is known as the mating restriction scheme that is applied with RC-GA to prevent individuals in different niches from mating with each other. If this Euclidean distance is smaller than an empirical user-defined critical distance known as niching radius, these solutions then compete against each other for selection for subsequent crossover basing on the comparison of fitness values. In this way, only solutions in same region (or niche) are considered, and so increasing the probability to achieve the near global optimum solution.

RC-NGA flowchart for optimising Reference Frame is shown in Fig. 10. Penalty functions were used to address constraints and thus define the relationship between the objective function and constraints. This effectively transforms a constrained problem to an unconstrained one and defines the fitness function used to assess the quality of the solutions the genetic algorithm evolves. In this paper, the optimisation process using RC-NGA was executed with genetic parameters as follows: number of generations $=200$; niching radius $=$ 0.25 ; mutation probability $=0.1$; crossover probability $=0.9$. The evolutionary process was set to terminate after a predefined number of generations.

\section{Validation of RC-NGA}

In this section, the proposed algorithm is validated against the exact optimum solution determining from exhaustive enumeration. Some assumptions are applied in this design example for simplifying the optimisation process:

- Fixed building topology: $\mathrm{b}_{\mathrm{f}}=6 \mathrm{~m}$ and $\theta_{\mathrm{f}}=10^{\circ}$

- Rigid joints applied at the eaves and apex (Fig. 1(a))

- Frame members with full lateral restraint.

With these assumptions, material cost of secondary members and frame joints are therefore excluded from the cost function. The optimisation problem has two discrete decision variables, namely, the cross-section sizes for column and rafter members. It should be noted that owing to full lateral restraint applied to the primary members, the design constraint for lateral torsional buckling, namely, $\mathrm{g}_{3}$ and the three design constraints for secondary members, namely, $\mathrm{g}_{7}, \mathrm{~g}_{8}$ and $\mathrm{g}_{9}$ are deactivated from the design process.

The optimum cross-section size for the columns and rafters are chosen from a list of 36 options of cold-formed steel cross-sections used for the frame members, including both single sections (C) and back-to-back channelsections (BBC) that minimises the unit cost of the frame. The searching process with exhaustive enumeration is carried out to all permutation of sections that are used for column and rafter members.

It was found that the cross section BC-30030 was the best solution having a minimum cost of $£ 6.70$ per $\mathrm{m}^{2}$. The critical design constraint was obtained for the local capacity check of the column at eaves, under the ultimate load combination ULC2 (i.e., $\mathrm{g}_{2}=-0.16$ ). It is worth noting that searching the optimum design using exhaustive enumerate method generally is time-consuming and applied for simple design procedure only. 
The RC-NGA is then applied for searching for the optimum cross-section for the members of the frame. The optimisation process is proceeded with three different population sizes, namely 40,60 , and 80 respectively to investigate the RC-NGA's consistency. The probabilities for crossover and mutation operators used in the RCNGA are 0.9 and 0.1 , respectively. It was empirically found that the niching radius of 0.3 is suitable for selection and crossover operators, which work effectively to maintain the diversity of the population through generations in the evolutionary process. The optimisation was terminated after 200 generations.

The convergence history obtained from the RC-NGA is shown in Fig. 11. As can be seen, the progress of RCNGA from three runs with different populations converged to the same optimum solution within predefined 200 generations. As expected, three runs using different population sizes generated the same minimum-cost solution as obtained in the exhaustive enumeration search. This result has proved the reliability of proposed optimum algorithm. It was observed that the optimisation process took 8000 function evaluations to converge into optimum solution; results indicated that cost optimisation is improved when population size increases, although the computational time increases substantially.

\section{Optimisation of frame having rigid joints including effect of secondary members}

\subsection{Reference Frame with fixed topology}

In this section, Reference Frame is optimised incorporating the effect of secondary members, in which material cost of both primary and secondary members per unit floor area for one full bay of the building is minimised. It should be noted that if the layout of purlins and side rails spacing is fixed. In this paper, the best design of framing system is determined, using RC-NGA to select the most appropriate solution for discrete variables as follows:

- Cross-section sizes for the primary members

- Cross-section sizes and numbers of purlins and side rails (Table 4)

The population size of 80 candidates is selected for the evolutionary process, empirically chosen through a number of trials. The same genetic parameters used in previous optimal design are applied in this design example. To verify further the capacity of RC-NGA, the frame was optimised five times with different random seeds. The convergence progress of five optimisation runs is shown in Fig. 12.

It can be seen that the five runs converged to the same optimum solution within 200 generations. It is interesting to observe that seeds 2 and 5 randomly searched for the optimum solution with higher fitness values than remaining seeds from the first generation. This explained the reason of the evolutionary processes for seeds 2 and 5 converging to the optimum solution slower than those of seeds 1, 3, and 4 . As can also be seen from Fig. 12 , the evolutionary process took approximately 12500 function evaluations to converge into the optimum solution. The minimum unit cost obtained was $£ 24.70$ per $\mathrm{m}^{2}$, which the material cost each component is shown in Table 5. It is interesting to observe that main frame accounted for $27 \%$ of total material cost; the cost of purlins and side rails accounted for $26 \%$; the cost of claddings is the biggest accounting for $47 \%$. It was obtained from the optimum process that the same cross section of BBC 30030 was obtained for both columns and rafters. Also, the optimum cross-section for both purlins and side rails is Z-14016 with the optimum spacing of $1.20 \mathrm{~m}$. 
It is observed that the critical constraint of combined bending and compression on the column at the eaves under the load combination ULC2 governed the frame design, i.e., $\mathrm{g}_{2}=-0.16$, whilst the constraints of serviceability limits were still slack. This finding indicates the fact that standard topology chosen does not generate the cost-effective design, since all critical constraints obtained are smaller than their upper bounds. Therefore, the variation of frame spacing and pitch would produce a frame working more effectively, i.e. near full strength capacity of members, and so the target for a cost-effective design would be achieved.

\subsection{Reference Frame with variable topology}

In this section, the effect of building topology on optimum design of Reference Frame is considered, through varying pitch, $\theta_{\mathrm{f}}$, and frame spacing, bf within the range as mentioned in Section 4 . The design variables for this optimisation are as follows:

- Cross-section sizes for the primary members

- Cross-section sizes and numbers of purlins and side rails

- Topology: frame spacing and pitch

As can be seen, this design is more complicated than previous problems because the solution space is significantly larger owing to more decision variables. The optimisation is carried out ten times to check for the consistency of the results obtained. It is worth noting that the robustness and reliability of RC-NGA can be enhanced through maintaining the diversity of population for every generation, and this effect is achieved from adjusting niching radius.

For the niching radius larger than 0.5 , it is observed that the diversity of population was not maintained effectively. Interestingly, for the niching radius of unity, the population in the final generation was dominated by the solutions with best fitness values. Therefore, the optimisation process prematurely converged into a local optimum solution. It is observed that the robustness of RC-NGA was effectively achieved in searching for the optimum solution with a niching radius value of 0.25 ; population size of 120 is empirically found to be appropriate in searching the optimum solution in terms of the balance between the reliability and computational time. The lowest unit cost obtained from ten runs was shown in Table 5.

In comparison with the optimum design of Reference Frame with fixed topology, it is observed from Table 5 that the unit cost of optimum frame is around $15 \%$ lower and purlins and side rails unit cost is slightly $5 \%$ lower. This is because the optimum cross-section sizes of primary and secondary members are smaller, which is C-30030 for columns and rafters and Z-14014 for purlins and side rails. Small optimum frame spacing of $3.6 \mathrm{~m}$ was obtained, while the optimum pitch is still around the typical pitch of $10^{\circ}$.

As expected, the critical constraint achieved for lateral torsional buckling on the rafter at eaves is active, i.e. $g_{3}$ $=-0.01$, under the action of load combination ULC 2 . The design constraints of both ultimate and serviceability limit states indicate that a better effective design was obtained, as compared against the design of such frame with a fixed topology. The constraints for secondary members show that the smallest size of cold-formed steel Z-sections still work far lower than its strength capacity.

\subsection{Effect of joint configuration with knee braces}


In the previous section, it has been shown that incorporating the effect of building topology can produce a costeffective design of both primary and secondary members of CFS portal framing system. In this section, the parametric study is carried out on frames having different spans to investigate further the effect of rigid-joint configurations, i.e. joints with knee braces (Fig. 1(b)), on the optimum design. It is worth noting that the knee brace member is assumed to carry axial force only with geometry of knee arrangement as shown in Fig. 5(b). Portal frames considered for parametric study have the geometries as follows:

- Frame span ( $\left.\mathrm{L}_{\mathrm{f}}\right): 6 \mathrm{~m}, 8 \mathrm{~m}, 10 \mathrm{~m}, 12 \mathrm{~m}, 15 \mathrm{~m}, 18 \mathrm{~m}$ and $20 \mathrm{~m}$

- Column height $\left(\mathrm{h}_{\mathrm{f}}\right): \mathrm{Lf}_{\mathrm{f}} / 3$ and $\mathrm{Lf}_{\mathrm{f}} / 4$

For each frame, the optimisation is carried out with 2 design options, namely ultimate limit state (ULS), and ultimate and serviceability limit states (ULS+SLS). For ULS design only, it should be that deflection limits for steel portal frames are not specified in the British Standards (as well as other National Standards), and the decision as to whether or not a portal frame satisfies serviceability deflections is left to the judgement of the engineer. A typical explanation for this specific exclusion of deflection limits for portal frames is that deflections of portal frames have no direct significance on the serviceability of the frame itself. Although this explanation is technically correct, excessive deflections will affect, among other things, the serviceability of the cladding, water-tightness and the visual acceptability of the building in general.

Decision variables for this design example are the same as those used in Section 7.2. The genetic parameters used for the optimisation process are as follows: population $=120$; termination criterion $=200$ generations. Again, RC-NGA was run ten times with different seeds generated randomly to check for the consistency of the obtained results.

It was observed that RC-NGA successfully converged into the optimum solution within a predefined number of generations. Each optimum design took approximately 30,000 function evaluations to converge into the optimum solution. It is interesting to observe that the same design was obtained for purlins and side rails, in which the optimum cross-section is Z-14014 with spacing of around $1.2 \mathrm{~m}$. This is because owing to the optimum frame spacing obtained for all cases of parametric study smaller than $6 \mathrm{~m}$ (see Fig. 13), whilst optimum pitch is still around $10^{\circ}$.

Material cost of the primary members obtained from RC-NGA optimally designed with both rigid joint configurations is shown in Fig. 14. It should be noted that frame using rigid-joint configuration without knee braces is referred to as Type 1 and configuration with knee braces is referred to as Type 2 .

As can be seen, for frame using joint Type 1, material cost increases considerably when frame span is larger than $12 \mathrm{~m}$ under ULS+SLS design option. Especially, for frame span of $20 \mathrm{~m}$ and $\mathrm{L}_{\mathrm{f}} \mathrm{h}_{\mathrm{f}}$ of 3 (see Fig. 14(b)), the unit cost under the optimum design with ULS+SLS is higher than ULS design by $90 \%$. However, such significant difference is not obtained for frames using Type 2 joint configuration. This finding indicates the fact that using joint configuration with knee braces shows a significantly advantage on the unit cost of main frames, especially to frame spans larger than $12 \mathrm{~m}$. For CFS portal frames having modest spans, i.e. less than $12 \mathrm{~m}$, the use of knee braces would not show any significant benefit in improving the structural performance.

For ULS+SLS design option, it was observed that the design constraint of horizontal deflection at the eaves governed the optimum designs of frames using Type 1 joint configuration, whilst ultimate constraints 
controlled in most design cases of frames Type 2 for modest spans. However, it was also observed that for the column height larger than $5 \mathrm{~m}$ and frame span larger than $15 \mathrm{~m}$, horizontal deflection at eaves controlled the optimal designs of frames Type 2. Fig. 15 shows the percentage of unit cost for each component for one bay of the building, namely frame members, purlins and side rails, and cladding. This result again shows the importance of including secondary members into the design of CFS portal frame buildings having modest spans, i.e. smaller than $12 \mathrm{~m}$.

\section{Effect of semi-rigid joints on optimum design of Reference Frame}

In this section, the joint configuration having semi-rigidity and partial strength as shown in Fig. 4 is applied for the eaves and apex joints of Reference Frame. Parameters used to define semi-rigid joints of main frame are shown in Fig. 9. As can be seen, the rotational stiffness at the eaves of the bolt-group connecting the column and rafter to the eaves bracket are $\mathrm{k}_{\mathrm{ec}}$ and $\mathrm{k}_{\mathrm{er}}$, respectively. Similarly, the rotational stiffness at the apex of the bolt-group connecting the rafter to the apex bracket is $\mathrm{kar}$.

The stiffness of such joint configuration is determined using Eq. 1 basing on the dimensions of bolt-group. It should be noted that the breadth of bolt-group is calculated from the height of CFS cross-sections being used for column and rafter members, whilst the length of bolt group is processed as continuous decision variables for design optimisation. The cost-effective design of Reference Frame is searched using RC-NGA to select the optimum solution for decision variables as follows:

- Discrete variables: cross-section sizes for columns and rafters using channel-sections; cross-section size for purlins and side rails using Z-section and number of purlins and side rails on the rafters and columns, respectively.

- Continuous variables: lengths of bolt-groups, i.e., $\mathrm{a}_{\mathrm{ecc}}$, aer, and $\mathrm{a}_{\mathrm{ar}}$ and building topology.

The frame is optimised ten times with initially different random seeds to verify the consistency of the RCNGA's solutions. Also, the influence of joint flexibility on the optimum design is investigated through two design options as follows:

- Ultimate limit state (ULS)

- Ultimate + serviceability limit states (ULS+SLS)

It was observed that the optimum solution is obtained within the pre-defined number of generations after ten runs. For ULS+SLS design option, it is obtained that the optimum frame spacing is $3.3 \mathrm{~m}$, which is $8.3 \%$ shorter than that of design with rigid joints (Type 1), whilst the optimum cross section for primary members is the same for both joint configurations. The constraint of the horizontal deflection at the eaves under SLC2 with WLC4 now governs, i.e. $g_{10}=0$. It can be expected that the serviceability governs since the flexibility of the frame has increased. Details of optimum design for semi-rigid joint are shown in Table 6.

It is observed in Table 6 that albeit the eaves joint is usually subjected to the highest bending moments in the portal frame, the ridge joint is also required to have a high rigidity for ULS design option to carry a reasonable bending moment redistributed from bending moment at the eaves joint. Interestingly, such moment redistribution can reduce the cost of primary members up to $16.4 \%$ (see Table 7). However, the optimum design with ULS+SLS option generated a bracket size of the eaves joints around twice as large as that of apex 
joint, to reduce the horizontal deflection of frame. It should be noted that no cost for the brackets is assumed for the rigid-joint frame, as the only purpose of considering this frame type is to compare the column and rafter members against those selected for frames designed taking into account semi-rigid joints. Further designs for different frame spans show that there is not feasible solution for such frame using semi-rigid joint configuration with large spans, i.e. $15 \mathrm{~m}$.

\section{Conclusion}

The optimum design of cold-formed steel portal framing system was conducted, and the influence of rigid and semi-rigid joint configurations on frame design was considered. The effect of secondary members, i.e. purlins and side rails on building topology was also investigated. A genetic algorithm was adopted for the optimisation process which showed robustness and reliability in searching for a cost-effective design of CFS portal frame.

For rigid joint configurations, optimum frame spacing for CFS portal frames would be smaller than $6 \mathrm{~m}$, which could reduce the cost of primary members up to $15 \%$. The use of knee braces shows a slight enhancement of frame performance CFS portal frames with modest spans, i.e. less than $12 \mathrm{~m}$. However, when frame span becomes larger than $15 \mathrm{~m}$, significant improvement was obtained. For frames having modest span, the percentage of secondary members in the total cost is considerable, and so accounting for such effect into the design of CFS portal framing system become necessary.

For semi-rigid joint configuration, the optimum design on Reference Frame having span of $12 \mathrm{~m}$ showed that design constraint of serviceability limit governed. As expected, a large size of brackets at eaves joints can effectively reduce the horizontal deflection. However, when the serviceability limit state is neglected, the larger size of the apex bracket should be adopted for taking the bending moment redistributed from the eaves joints. The effect of flexibility and partial strength on semi-rigid joint configuration with knee brace will be carried out for future research for its consistence with Eurocode 3. 


\section{References}

ANSYS Inc., (2009). Programmer's manual for mechanical APDL. USA: SAS IP.

AS/NZS4600 (2005). Cold-formed steel structures. Autralian/New Zealand Standard, Standards Australia Limited/Standards New Zealand, Sydney.

BS 5950 (1998). Structural use of steelworks in building-Part 5: Code of practice for design of cold-formed thin gauge sections. British Standards, British Standards Institution, London.

British Standard, (2000). BS 5950: Structural use of steelworks in building. Part 1. Code of practice for design - Rolled and welded sections. London: British Standards Institution.

BS 6399 (2002). Loading for buildings. British Standards, British Standards Institution, London.

Davies JM (1991). Connections for cold-formed steelwork. In: Design of Cold-Formed Steel Members (Rhodes J, Editor), Elsevier Applied Science, London and New York.

Deb, K., (2000). An efficient constraint handling method for genetic algorithms. Computer Methods in Applied Mechanics and Engineering, 186: 311-338.

Deb, K., (2001). Multi-objective optimization using evolutionary algorithms. Chichester: John Wiley and Sons Inc.

Dubina, D., Ungureanu, V., and Landolfo, R. (2012). Design of Cold-formed Steel Structures. Berlin: WileyBlackwell.

Gilbert, B. P., Savoyat, T. J-M. and Teh, L.H., (2012a). Self-shape optimisation application: Optimisation of cold-formed steel columns. Thin-Walled Structures, 60: 173-184.

Gilbert, B. P., Teh, L.H., Guan, H., (2012b). Self-shape optimisation principles: Optimisation of section capacity for thin-walled profiles. Thin-Walled Structures, 60: 194-204.

Issa, H.K., and Mohammad, F.A., (2010), "Effect of mutation schemes on convergence to optimum design of steel frames", Journal of Constructional Steel Research, 66(7), 954-961.

Kirk, P. (1986). Design of a cold-formed section portal frame building system. Proc. 8th International Specialty Conf. on Cold-formed Steel Structures. St Louis, Missouri: University of Missouri-Rolla, 295-310.

Kulak, G.L., J.W. Fisher and J.H.A. Struik, (1987). Guide to Design Criteria for Bolted and Riveted Joints, Second Edition, John Wiley \& Sons, New York, NY.

Lim, J.B.P., and Nethercot, D.A., (2003). Serviceability design of a cold-formed steel portal frame having semi-rigid joints. Steel and Composite Structures, 3: 451-474.

Lim, J.B.P. and Nethercot, D.A. (2004). Finite element idealization of a cold-formed steel portal frame. Journal of Structural Engineering, ASCE, 130: 78-94.

Ma, W., Hajirasouliha, I., Becque, J., Ye, J., (2015). Cross-sectional optimization of cold-formed steel channels to Eurocode 3. Engineering Structures, 101: 641-651.

Michalewicz, Z., (1992). Genetic Algorithm + Data Structures = Evolution Programs. New York: SpringerVerlag. 
Mills, J. and LaBoube, R., (2004). Self-Drilling Screw Joints for Cold-Formed Channel Portal Frames. Journal of Structural Engineering, ASCE, 130(11): 1799- 1806.

Phan, D.T., Lim, J.B.P., Tanyimboh, T.T., Lawson, R.M., Martin, S., and Sha, W., (2013). Effect of serviceability limit on optimal design of steel portal frames. Journal of Constructional Steel Research, 86: 7484.

Phan, D.T., Lim, J.B.P., Sha, W., Siew, C.Y.M., Tanyimboh, T.T., Issa, H.K., and Mohammad, F.A., (2013). Design optimization of cold-formed steel portal frames taking into account the effect of topography. Engineering Optimization, 45: 415-433.

Phan, D.T., Lim, J.B.P., Tanyimboh, T.T., Wrzesien, A.M., Sha, W. and R.M., Lawson, (2015). Optimal design of cold-formed steel portal frames for stressed-skin action using genetic algorithm. Engineering Structures, 93: 36-49.

McKinstray, R., Lim, J.B.P., Tanyimboh, T.T., Sha, W., Phan, D.T., (2015a). Optimal design of long-span steel portal frames using fabricated beams to Eurocode. Journal of Constructional Steel Research, 104: 104114.

McKinstray, R., Lim, J.B.P., Tanyimboh, T.T., Phan D.T., Wei Sha, Brownlee, A.E.I., (2015b). Topographical optimisation of single-storey non-domestic steel framed buildings using photovoltaic panels for net-zero carbon impact. Building and Environment 86: 120-131.

McKinstray, R., Lim, J.B.P., Tanyimboh, T.T., Phan D.T., Sha, W., (2016). Comparison of optimal designs of steel portal frames including topological asymmetry considering rolled, fabricated and tapered sections. Engineering Structures, 111: 505-524.

Saka, M.P. (2003). Optimum design of pitched roof steel frames with haunched rafters by genetic algorithm. Computers and Structures, 81: 1967-1978.

SCI Advisory Desk (2010). AD-090: Deflection Limits for Pitched Roof Portal Frames (Amended). Ascot: The Steel Construction Institute.

Schafer, B.W., Li, Z., Moen, C.D., (2010). Computational modeling of cold-formed steel. Thin-Walled Structures, 48: 752-762.

Steadmans, (2012a). Purlins, rails and eaves beams. Cumbria: Steadmans and Son.

Steadmans, (2012b). Single skin system. Cumbria: Steadmans and Son.

Toropov, V.V., and Mahfouz, S.Y., 2001. Design optimization of structural steelwork using genetic algorithm, FEM and a system of design rules. Engineering Computations. 18(3/4), 437-459.

Wang, B., Bosco, G.L., Gilbert, B. P., Guan, H., Teh, L.H., (2016a). Unconstrained shape optimisation of singly-symmetric and open cold-formed steel beams and beam-columns. Thin-Walled Structures, 104: 54-61.

Wang, B., Gilbert, B. P., Molinier A.M., Guan, H., Teh, L.H., (2016a). Shape optimisation of cold-formed steel columns with manufacturing constraints using the Hough transform. Thin-Walled Structures, 106: 75-92. Wrzesien, A.M., Lim, J.B.P., Nethercot D.A., (2012). Optimum Joint Detail for a General Cold-Formed Steel Portal Frame. Advances in Structural Engineering, 15(9):1623-1640 
Wrzesien, A.M., Phan, D.T., Lim, J.B.P., Hajirasouliha, I., Lau, H-H., and Tan, C.S., (2016). Effect of Stressedskin action on optimal design of cold-formed steel box-shaped portal frame buildings. International Journal of Steel Structures, 16(2), 299-307.

Ye, J., Hajirasouliha, I., Becque, J., Eslami, A., (2016a). Optimum design of cold-formed steel beams using Particle Swarm Optimisation method. Journal of Constructional Steel Research, 122: 80-93.

Ye, J., Hajirasouliha, I., Becque, J., Pilakoutas, K., (2016b). Development of more efficient cold-formed steel channel sections in bending. Thin-Walled Structures, 101: 1-13.

Zandanfarrokh, F. and Bryan, E.R. (1992). Testing and design of bolted connections in cold-formed steel sections. Proc. 11th International Specialty Conf. on Cold-formed Steel Structures. St Louis, Missouri: University of Missouri-Rolla, 625-662. 


\section{Figure captions}

Fig. 1 Rigid joint configuration with swages on web of CFS channel section

(a) Rigid joint

(b) Rigid joint with knee brace

Fig. 2 Semi-rigid joint configuration

(a) Semi-rigid joint at eaves

(b) Semi-rigid joint at apex

Fig. 3 Details of considered bolt-group with nine bolts

Fig. 4 Details of effective length of semi-rigid joints

(a) Eaves joint

(b) Apex joint

Fig. 5 General geometry of cold-formed steel portal frame

(a) Rigid jointed frame

(b) Rigid-jointed frame having knee braces at the eaves

Fig. 6 Details of cold-formed steel Z-section (Steadmans 2012a)

Fig. 7 Sleeved single span system for lateral restraints

Fig. 8 Wind load cases (WLCs)

Fig. 9 Parameters used to define semi-rigid joints of portal frame

Fig. 10 Flowchart of RC-NGA

Fig. 11 Progress of RC-NGA for validating with exhaustive enumeration method

Fig. 12 Progress of RC-NGA for Reference Frame with fixed topology

Fig. 13 Variation of optimum frame spacing $\left(b_{f}\right)$ over frame span $\left(L_{f}\right)$

Fig. 14 Effect of design options on minimum frame cost for different frame geometries

\section{Table captions}

Table 1: Load factors for design combinations at ULS and SLS designs

Table 2 Deflection limits for steel portal framing system

Table 3 Load table for cladding profile (Steadmans, 2012b)

Table 4 Dimensions and section properties of UK cold-formed steel Zed sections

Table 5 Minimum unit cost of Reference Frame with rigid joint and secondary members

Table 6 Optimum length of bolt group for semi-rigid joint designed with variable topology

Table 7 Material cost of frame members for Reference Frame having semi-rigid joints 


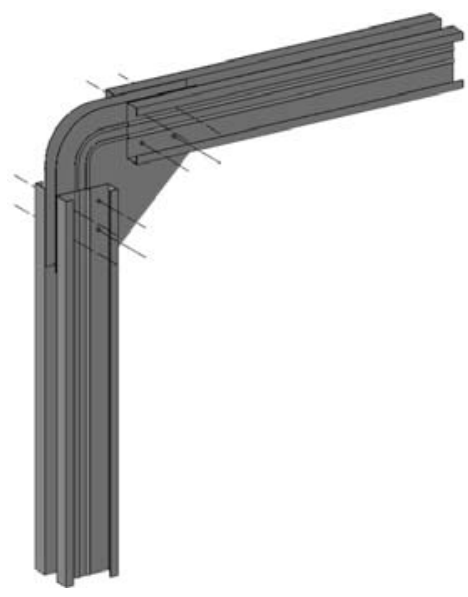

(a) Rigid joint

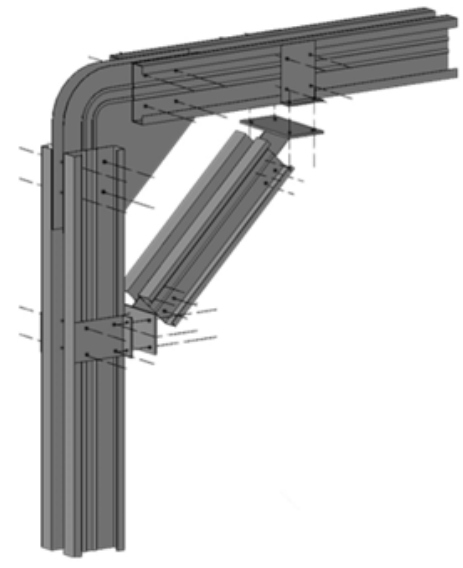

(b) Rigid joint with knee brace

Fig. 1 Rigid joint configuration with swages on web of CFS channel section

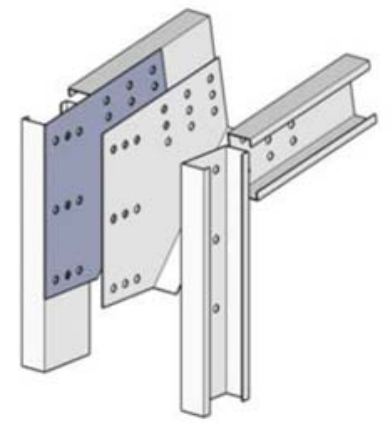

(a) Semi-rigid joint at eaves

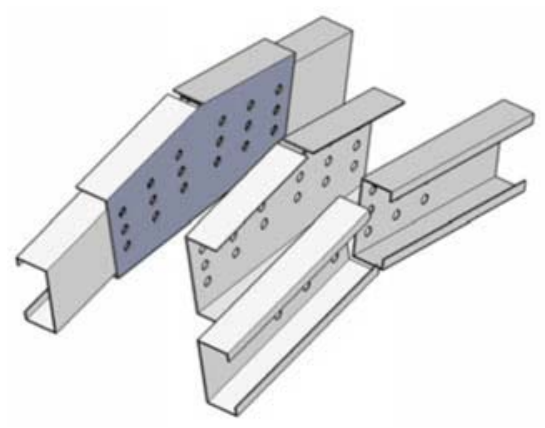

(b) Semi-rigid joint at apex

Fig. 2 Semi-rigid joint configuration 

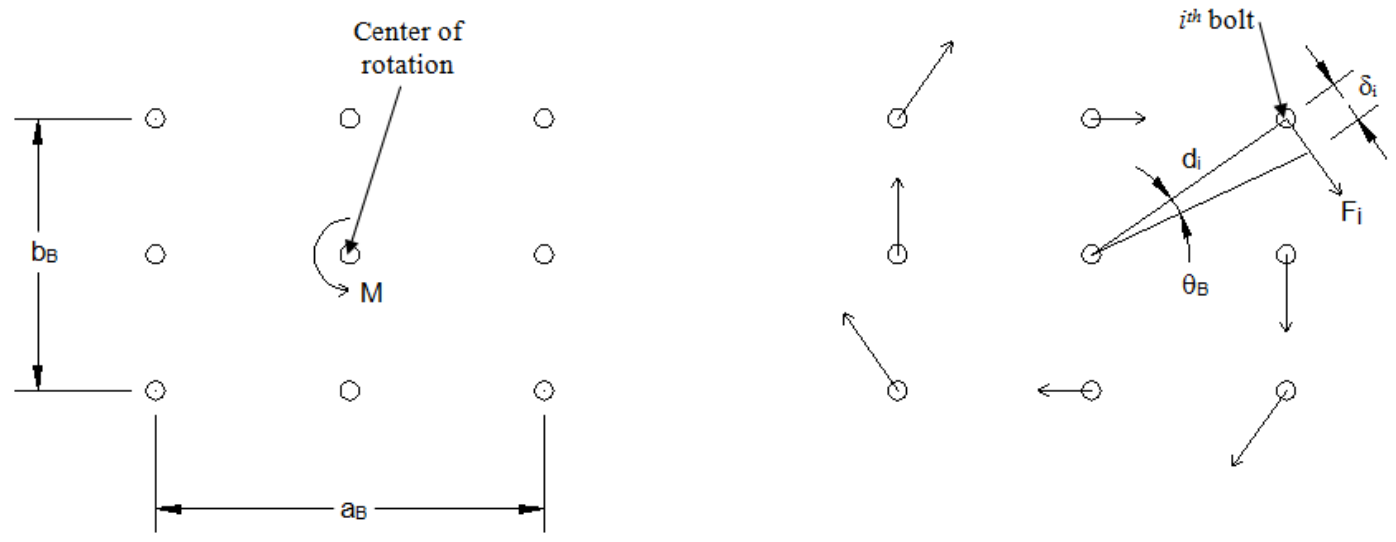

Fig. 3 Details of considered bolt-group with nine bolts

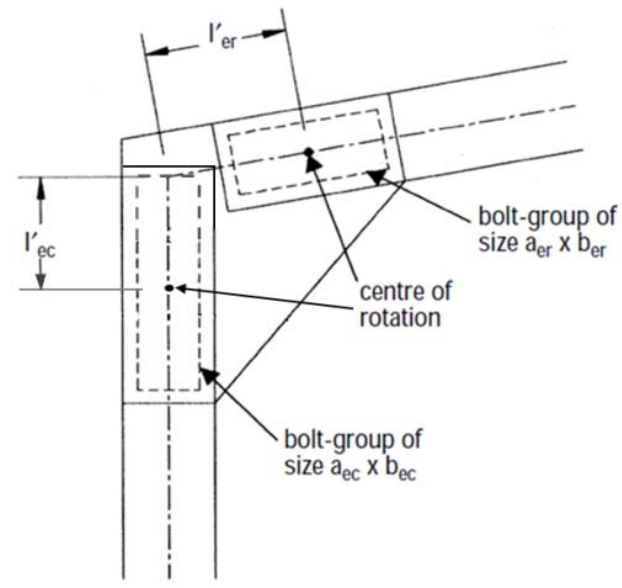

(a) Eaves joint

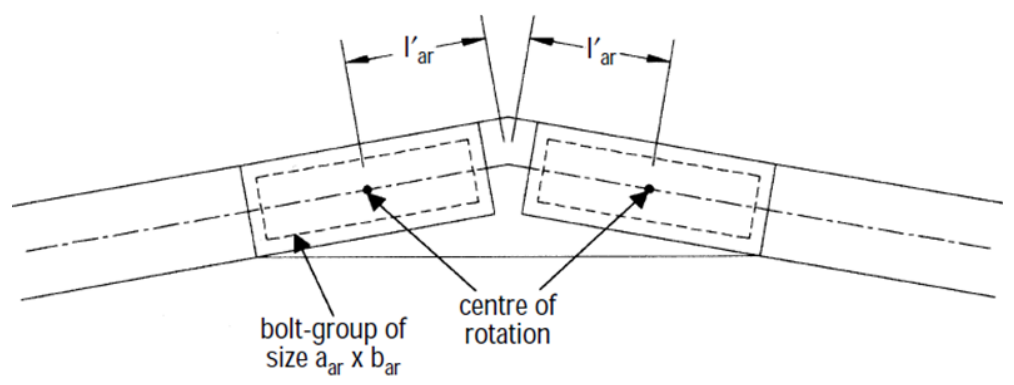

(b) Apex joint

Fig. 4 Details of effective length of semi-rigid joints 


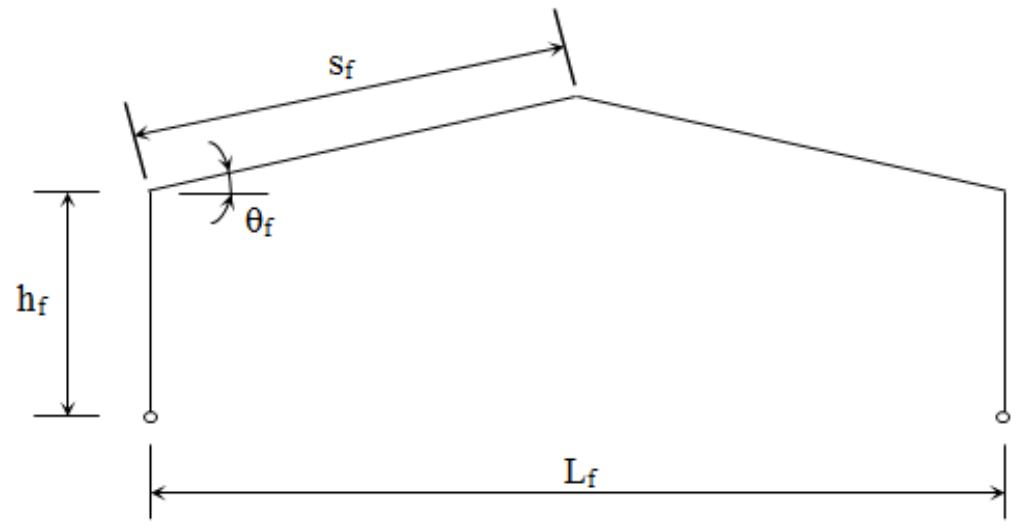

(a) Rigid jointed frame

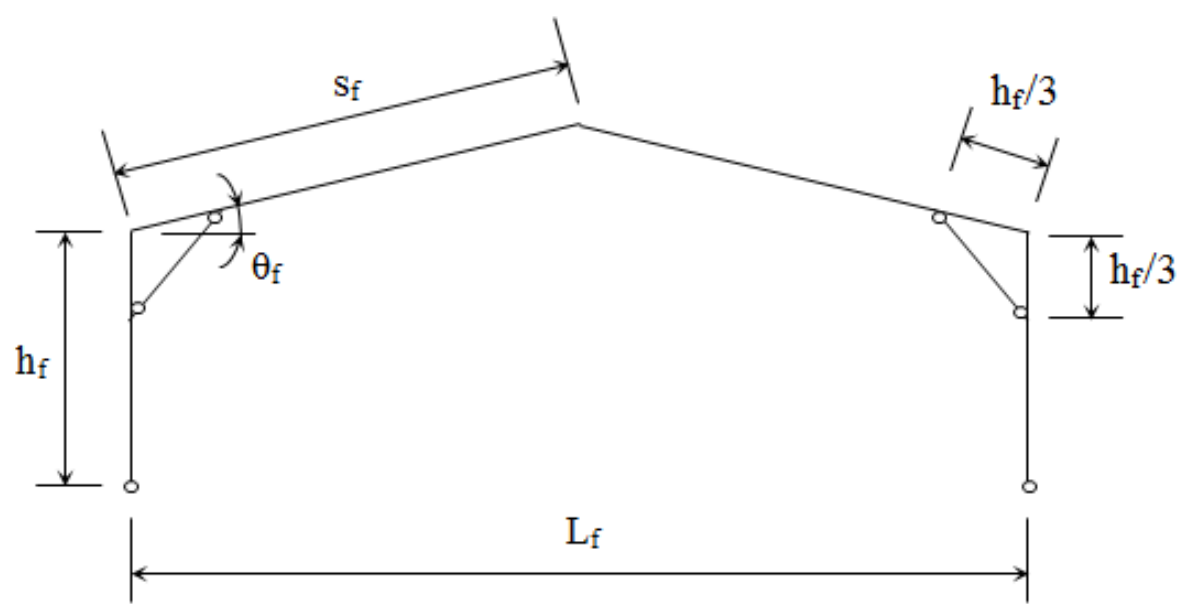

(b) Rigid-jointed frame having knee braces at the eaves

Fig. 5 General geometry of cold-formed steel portal frame 


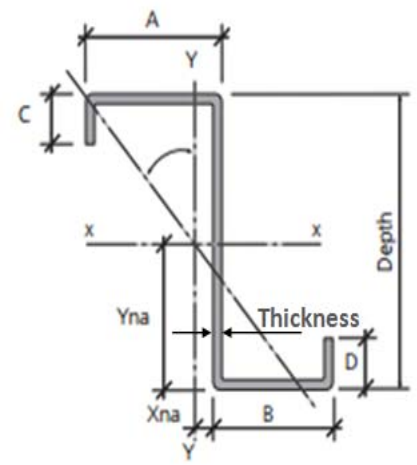

Fig. 6 Details of cold-formed steel Z-section (Steadmans 2012a)

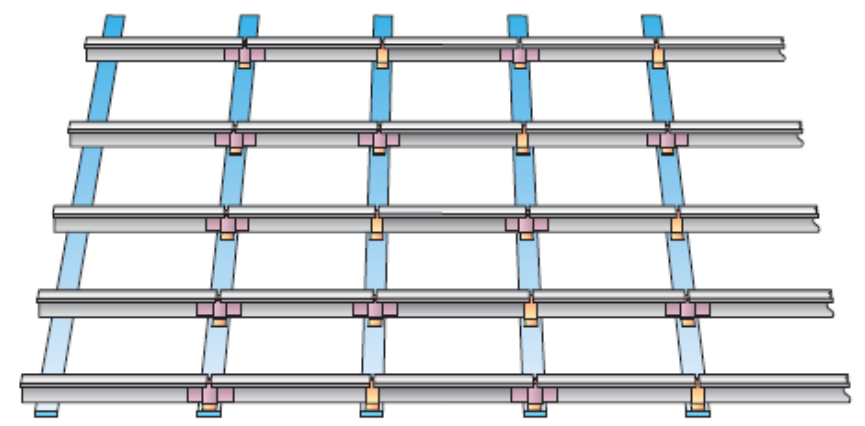

Fig. 7 Sleeved single span system for lateral restraints 


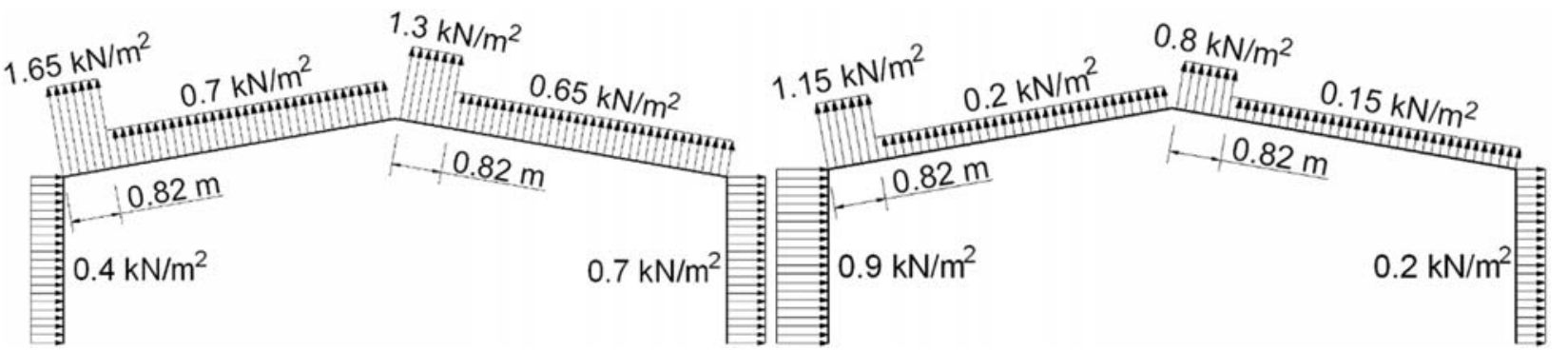

(a) WL1

(b) WLC2

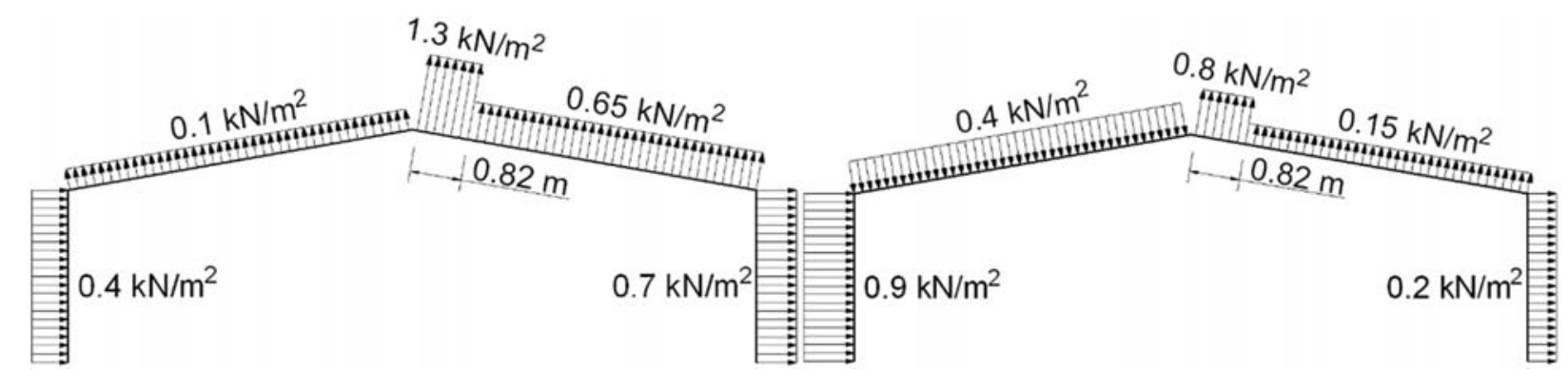

(c) WLC3

(d) WLC4

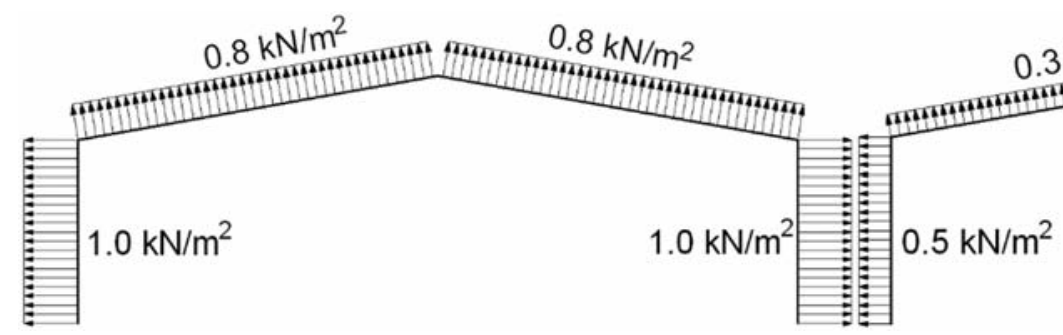

$0.3 \mathrm{kN} / \mathrm{m}^{2} \quad 0.3 \mathrm{kN} / \mathrm{m}^{2}$

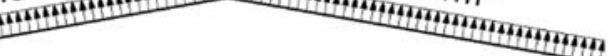

(e) WLC5

(f) WLC6

Fig. 8 Wind load cases (WLCs) 


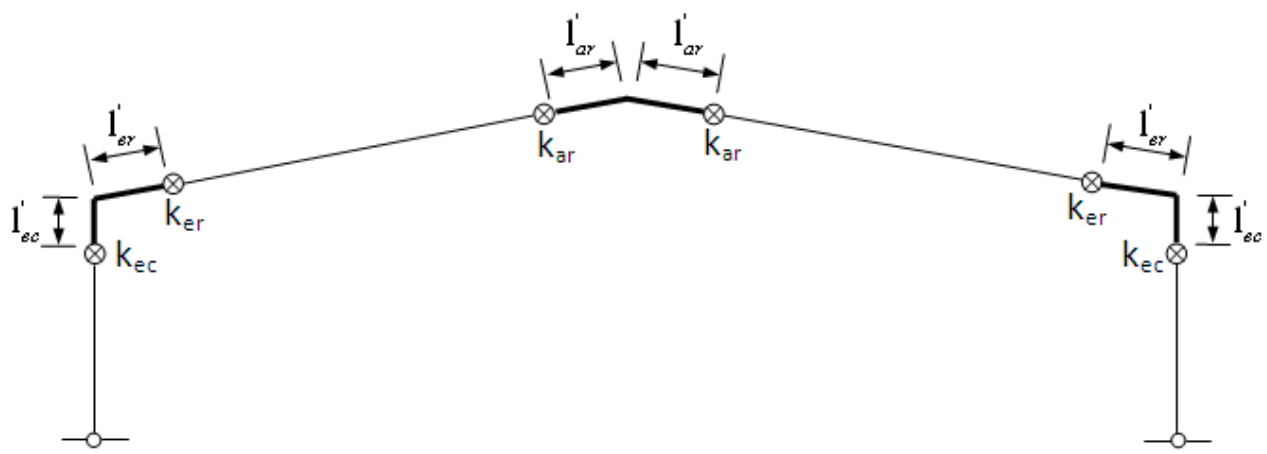

Fig. 9 Parameters used to define semi-rigid joints of portal frame

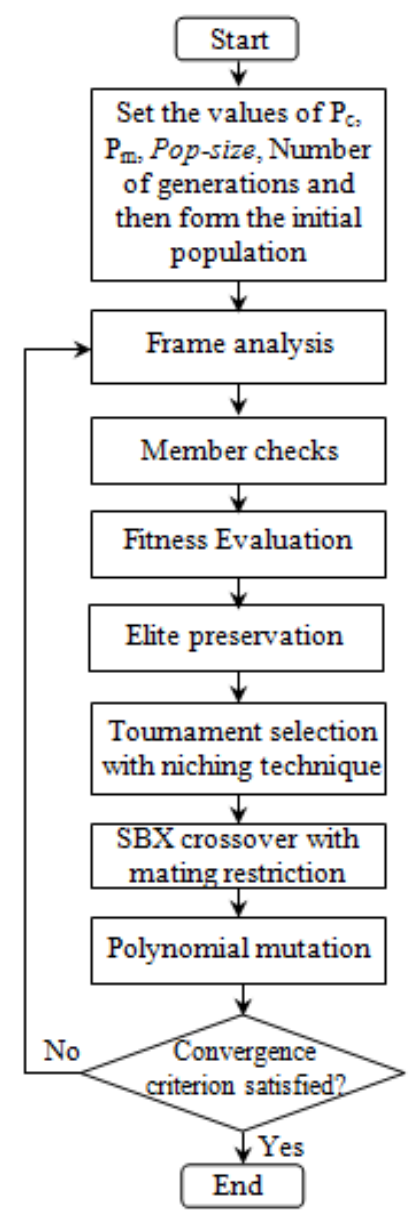

Fig. 10 Flowchart of RC-NGA 


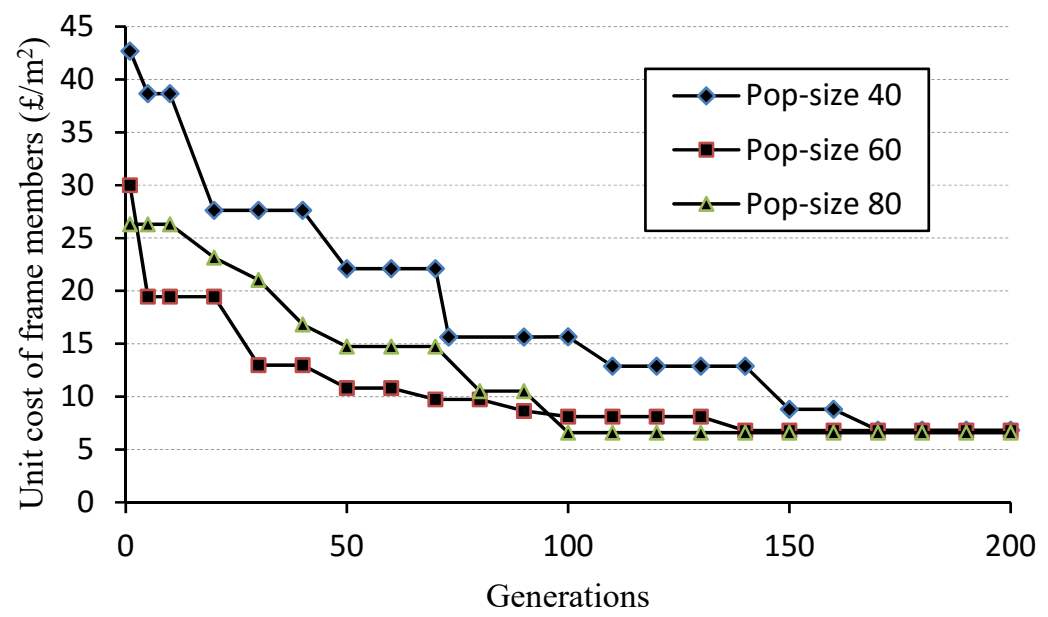

Fig. 11 Progress of RC-NGA for validating with exhaustive enumeration method

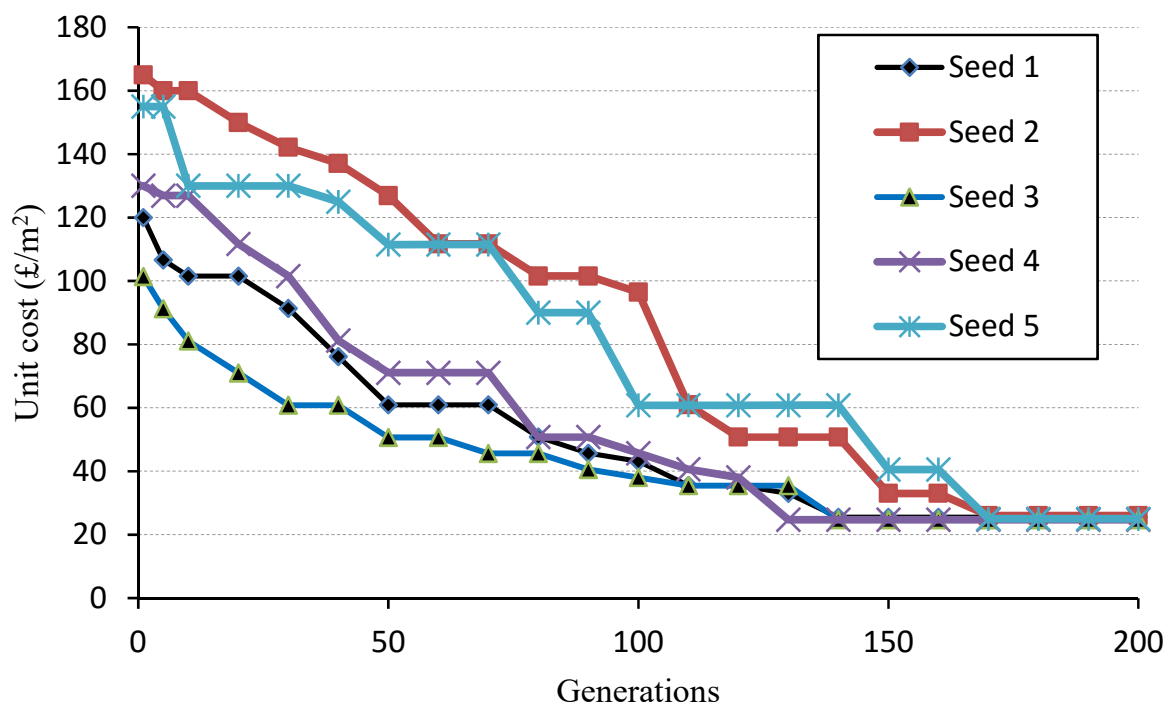

Fig. 12 Progress of RC-NGA for Reference Frame with fixed topology 


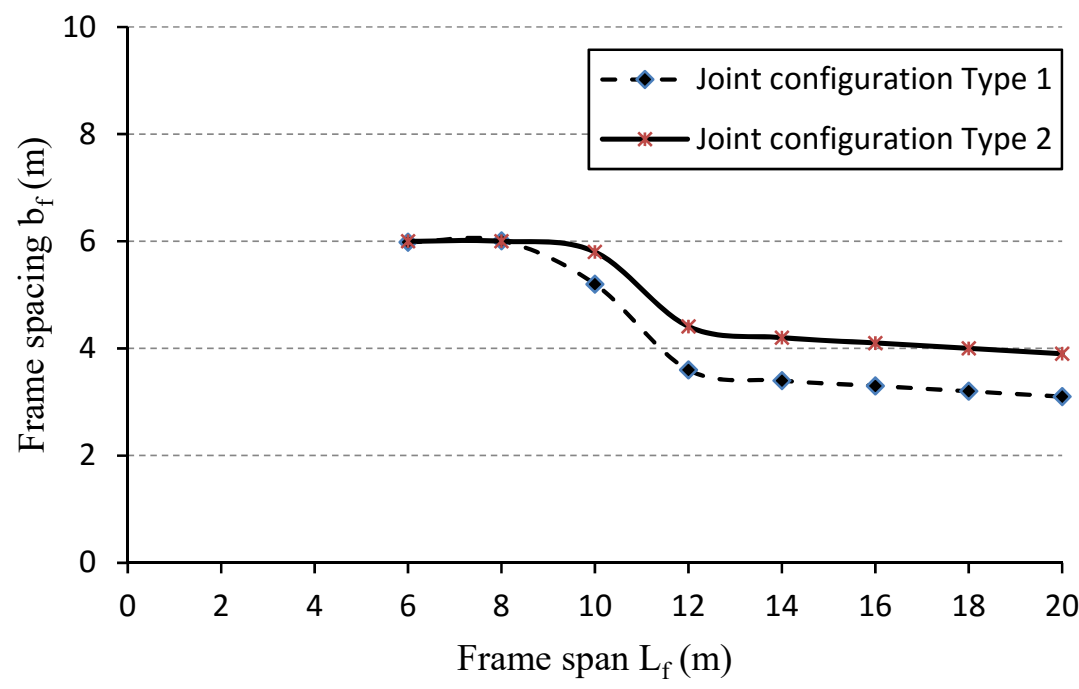

Fig. 13 Variation of optimum frame spacing $\left(b_{f}\right)$ over frame span $\left(\mathrm{L}_{\mathrm{f}}\right)$ 


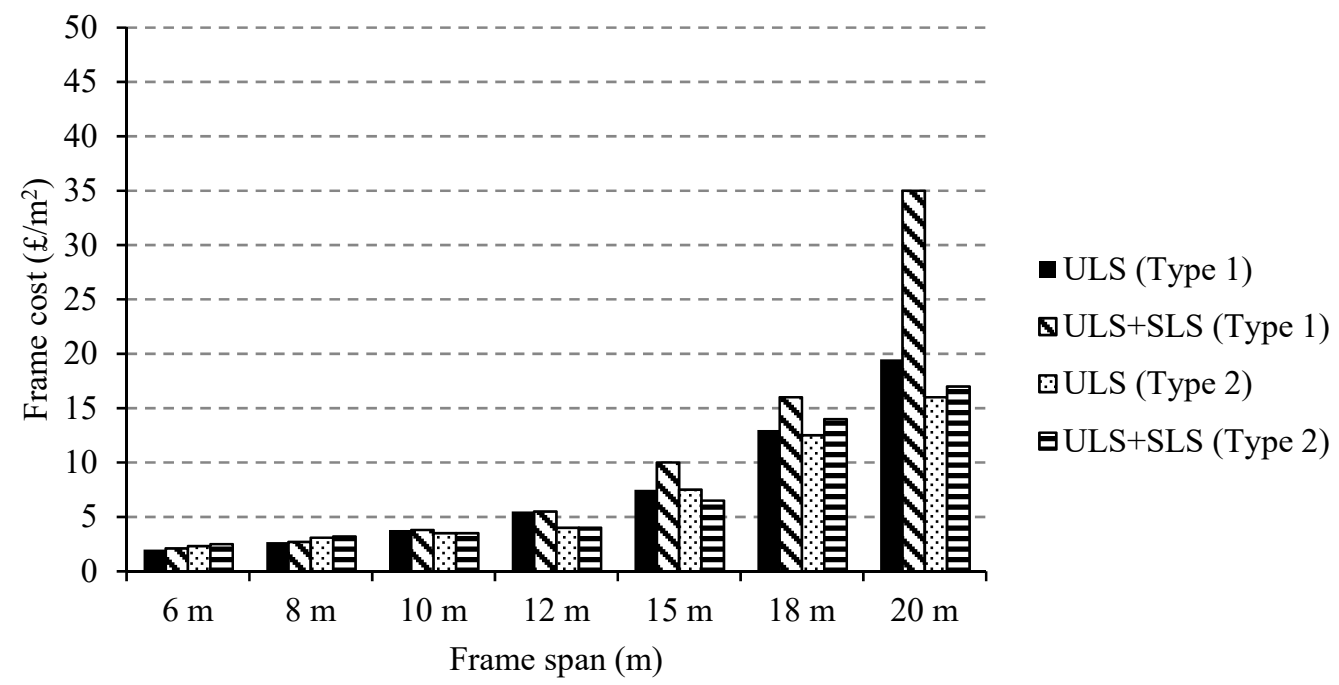

(a) $\mathrm{L}_{\mathrm{f}} / \mathrm{h}_{\mathrm{f}}=4$ and $\theta_{\mathrm{f}}=10^{\circ}$

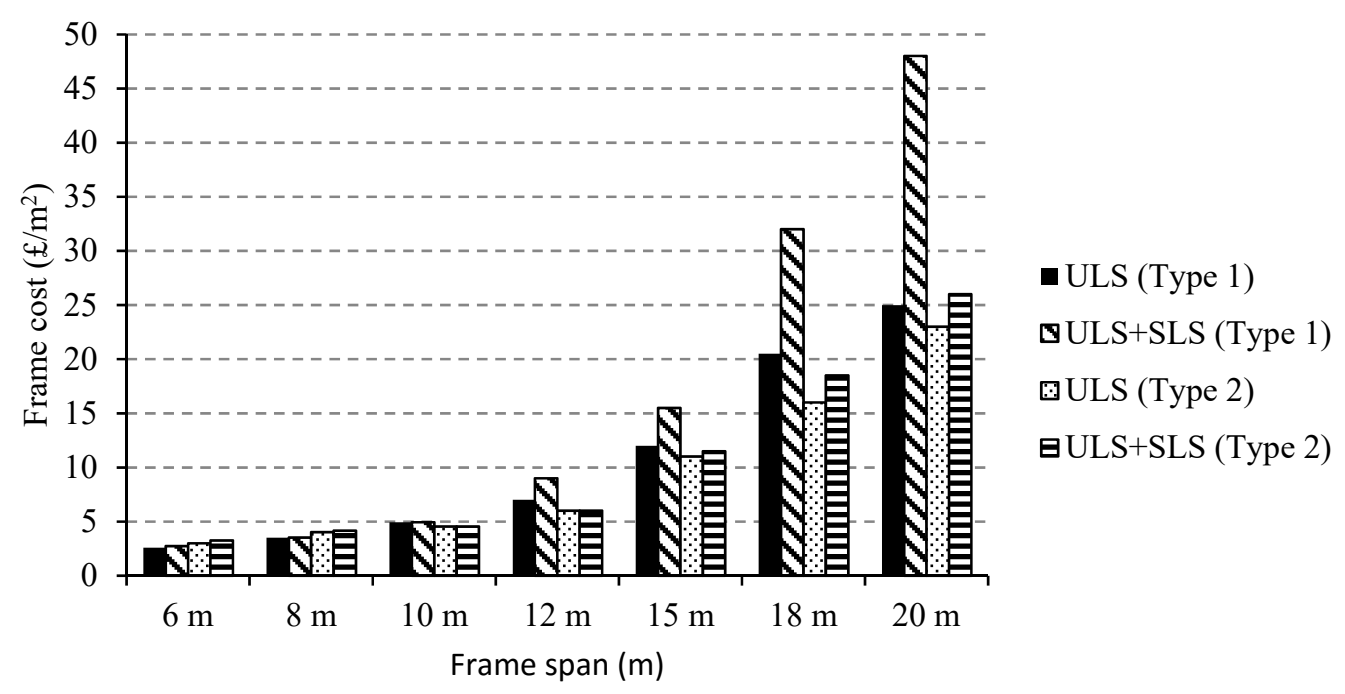

(b) $\mathrm{L}_{\mathrm{f}} / \mathrm{h}_{\mathrm{f}}=3$ and $\theta_{\mathrm{f}}=10^{\circ}$

Fig. 14 Effect of design options on minimum frame cost for different frame geometries 


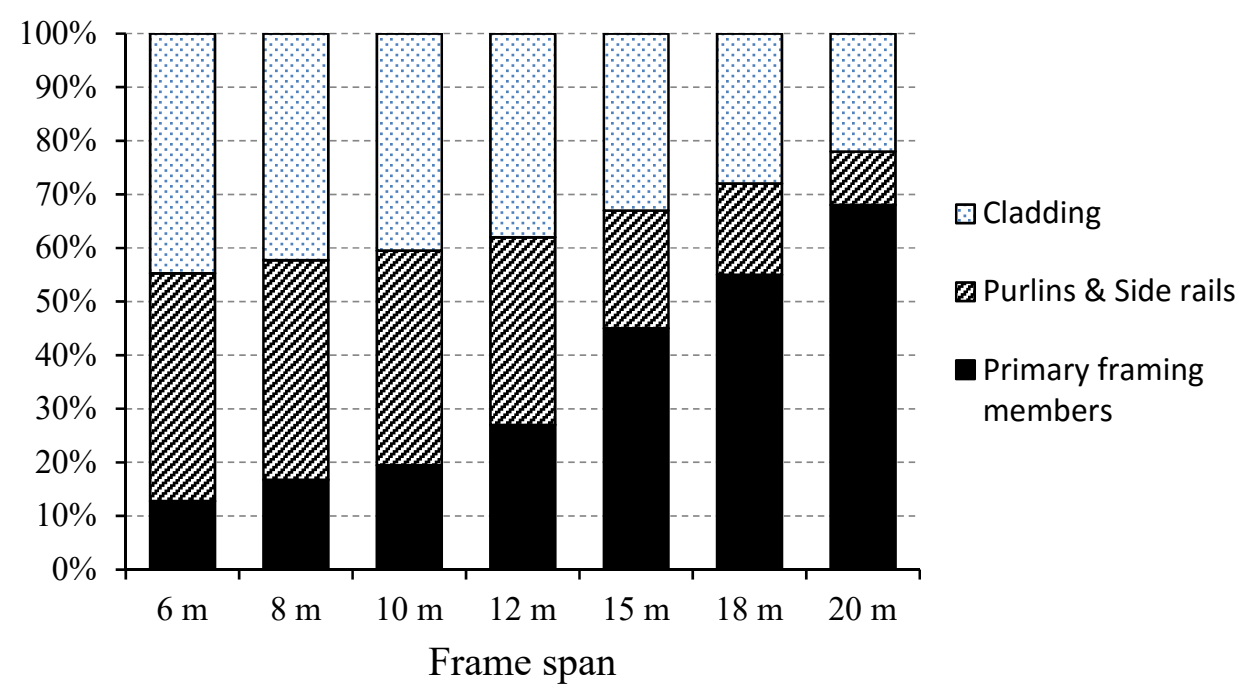

Fig. 15 Percentage of each component for one bay of cold-formed steel building 
Table 1: Load factors for design combinations at ULS and SLS designs

\begin{tabular}{|c|c|c|c|c|c|}
\hline Actions & $\begin{array}{l}\text { Load } \\
\text { combination }\end{array}$ & $\begin{array}{c}\text { Dead Load } \\
\text { (DL) }\end{array}$ & $\begin{array}{c}\text { Live Load } \\
\text { (LL) }\end{array}$ & $\begin{array}{c}\text { Wind Load } \\
\text { (WL) }\end{array}$ & $\begin{array}{c}\text { Wind Load } \\
\text { (uplift) }\end{array}$ \\
\hline \multirow{3}{*}{ Ultimate limit state } & ULC1 & 1.4 & 1.6 & - & - \\
\cline { 2 - 6 } & ULC2 & 1.2 & 1.2 & 1.2 & - \\
\cline { 2 - 6 } & ULC3 & 1.4 & 1.4 & - & - \\
\cline { 2 - 6 } & ULC4 & 1.0 & - & - & 1.4 \\
\hline \multirow{2}{*}{ Serviceability limit state } & SLC1 & - & 1.0 & - & - \\
\cline { 2 - 6 } & SLC2 & - & - & 1.0 & - \\
\hline
\end{tabular}

Table 2 Deflection limits for steel portal framing system

\begin{tabular}{|c|c|c|}
\hline \multirow{2}{*}{} & \multicolumn{2}{|c|}{ SCI Advisory Desk (2010) } \\
\cline { 2 - 3 } & $\begin{array}{c}\text { Absolute } \\
\text { deflection }\end{array}$ & $\begin{array}{c}\text { Differential deflection relative to } \\
\text { adjacent frame }\end{array}$ \\
\hline Lateral deflection at eaves & $\leq \frac{\mathrm{h}_{\mathrm{f}}}{100}$ & $\leq \frac{\mathrm{b}_{\mathrm{f}}}{200}$ \\
\hline Vertical deflection at apex & - & $\leq \frac{\mathrm{b}_{\mathrm{f}}}{100}$ and $\sqrt{\mathrm{b}_{\mathrm{f}}{ }^{2}+\mathrm{s}_{\mathrm{f}}}{ }^{2} / 125$ \\
\hline
\end{tabular}

Table 3 Load table for cladding profile (Steadmans, 2012b)

\begin{tabular}{|l|c|c|c|c|c|c|c|}
\hline Span $(\mathrm{m})^{(* *)}$ & 1.2 & 1.4 & 1.6 & 1.8 & 2.0 & 2.2 & 2.4 \\
\hline & \multicolumn{7}{|c|}{ Roof } \\
\hline Wind suction $\left(\mathrm{kN} / \mathrm{m}^{2}\right)$ & 2.58 & 1.91 & 1.47 & 1.17 & 0.95 & 0.79 & 0.67 \\
\hline Imposed load $\left(\mathrm{kN} / \mathrm{m}^{2}\right)$ & 1.36 & 1.07 & 0.87 & 0.72 & 0.60 & 0.51 & 0.44 \\
\hline & \multicolumn{7}{|c|}{ Wall } \\
\hline Wind suction $\left(\mathrm{kN} / \mathrm{m}^{2}\right)$ & 2.71 & 1.99 & 1.52 & 1.20 & 0.97 & 0.81 & 0.68 \\
\hline Wind pressure $\left(\mathrm{kN} / \mathrm{m}^{2}\right)$ & 1.56 & 1.23 & 1.00 & 0.83 & 0.70 & 0.60 & 0.52 \\
\hline
\end{tabular}

${ }^{(* *)}$ For purlins and side rails spacing

Table 4 Dimensions and section properties of UK cold-formed steel Zed sections

\begin{tabular}{|c|l|c|r|r|r|r|r|c|}
\hline No & Section & $\begin{array}{c}\text { Depth } \\
(\mathrm{mm})\end{array}$ & $\begin{array}{c}\text { Thickness } \\
(\mathrm{mm})\end{array}$ & $\begin{array}{c}\text { EA }\left(10^{2}\right) \\
(\mathrm{kN})\end{array}$ & $\begin{array}{c}\text { EIx }\left(10^{6}\right) \\
\left(\mathrm{kN.mm^{2 }}\right)\end{array}$ & $\begin{array}{c}\mathrm{M}_{\mathrm{cx}} \\
(\mathrm{kNm})\end{array}$ & $\begin{array}{c}\text { Weight } \\
(\mathrm{kg} / \mathrm{m})\end{array}$ & $\begin{array}{c}\text { Cost }^{(*)} \\
(\mathrm{f} / \mathrm{m})\end{array}$ \\
\hline 1 & Z14014 & 140 & 1.4 & 781.88 & 239.50 & 5.45 & 3.06 & 4.52 \\
\hline 2 & Z14016 & 140 & 1.6 & 892.65 & 271.97 & 6.63 & 3.48 & 4.73 \\
\hline 3 & Z14018 & 140 & 1.8 & 1002.96 & 304.17 & 7.75 & 3.90 & 5.31 \\
\hline 4 & Z14020 & 140 & 2.0 & 1113.03 & 336.21 & 8.75 & 4.32 & 5.81 \\
\hline 5 & Z17016 & 170 & 1.6 & 988.59 & 428.82 & 8.30 & 3.86 & 5.54 \\
\hline 6 & Z17018 & 170 & 1.8 & 1111.20 & 480.03 & 9.69 & 4.33 & 5.64 \\
\hline 7 & Z17020 & 170 & 2.0 & 1233.57 & 531.02 & 11.00 & 4.79 & 6.18 \\
\hline 8 & Z17025 & 170 & 2.5 & 1533.83 & 653.47 & 14.14 & 5.94 & 7.89 \\
\hline 9 & Z20015 & 200 & 1.5 & 1076.58 & 650.38 & 9.43 & 4.20 & 5.62 \\
\hline 10 & Z20016 & 200 & 1.6 & 1148.49 & 692.60 & 10.47 & 4.48 & 5.95 \\
\hline 11 & Z20018 & 200 & 1.8 & 1291.60 & 776.16 & 12.52 & 5.03 & 6.70 \\
\hline 12 & Z20020 & 200 & 2.0 & 1434.47 & 859.39 & 14.53 & 5.58 & 7.35 \\
\hline 13 & Z20025 & 200 & 2.5 & 1785.99 & 1060.51 & 18.97 & 6.92 & 9.10 \\
\hline 14 & Z24020 & 240 & 2.0 & 1643.41 & 1385.33 & 18.47 & 6.39 & 8.10 \\
\hline 15 & Z24025 & 240 & 2.5 & 2048.23 & 1713.24 & 24.45 & 7.94 & 11.10 \\
\hline 16 & Z24030 & 240 & 3.0 & 2447.17 & 2031.01 & 30.19 & 9.47 & 13.24 \\
\hline
\end{tabular}

${ }^{(*)}$ Cost was taken from the Steadmans in 2012 
Table 5 Minimum unit cost of Reference Frame with rigid joint and secondary members

\begin{tabular}{|c|c|c|c|c|}
\hline Topology & $\begin{array}{c}\text { Frame } \\
\left(£ / \mathrm{m}^{2}\right)\end{array}$ & $\begin{array}{c}\text { Purlins and side rails } \\
\left(£ / \mathrm{m}^{2}\right)\end{array}$ & $\begin{array}{c}\text { Cladding } \\
\left(£ / \mathrm{m}^{2}\right)\end{array}$ & $\begin{array}{c}\text { Total cost } \\
\left(£ / \mathrm{m}^{2}\right)\end{array}$ \\
\hline Fixed & 6.60 & 6.30 & 11.80 & 24.70 \\
\hline Variable & 5.60 & 6.00 & 11.80 & 23.40 \\
\hline
\end{tabular}

Table 6 Optimum length of bolt group for semi-rigid joint designed with variable topology

\begin{tabular}{|c|c|c|c|c|}
\hline \multirow{2}{*}{ Design option } & \multicolumn{2}{|c|}{ Length of bolt-groups } & Unit cost of bracket \\
& $\mathrm{a}_{\mathrm{ec}}$ & $\mathrm{a}_{\mathrm{er}}$ & $\mathrm{a}_{\mathrm{ar}}$ & $\left.1 \mathrm{~m}^{2}\right)$ \\
\hline $\mathrm{ULS}$ & $0.50 \mathrm{~m}$ & $0.51 \mathrm{~m}$ & $0.64 \mathrm{~m}$ & 1.10 \\
\hline ULS+SLS & $0.76 \mathrm{~m}$ & $0.87 \mathrm{~m}$ & $0.41 \mathrm{~m}$ & 1.50 \\
\hline
\end{tabular}

Table 7 Material cost of frame members for Reference Frame having semi-rigid joints

\begin{tabular}{|c|c|c|c|c|}
\hline Design option & $\begin{array}{c}\text { Frame members } \\
\left(£ / \mathrm{m}^{2}\right)\end{array}$ & $\begin{array}{c}\text { Purlins and side rails } \\
\left(£ / \mathrm{m}^{2}\right)\end{array}$ & $\begin{array}{c}\text { Cladding } \\
\left(£ / \mathrm{m}^{2}\right)\end{array}$ & $\begin{array}{c}\text { Total cost of members } \\
\left(£ / \mathrm{m}^{2}\right)\end{array}$ \\
\hline ULS & 5.10 & 6.00 & 11.80 & 22.90 \\
\hline ULS+SLS & 6.10 & 6.00 & 11.80 & 23.90 \\
\hline
\end{tabular}

